Peter A. Chapman

Tracking Number 141011

\title{
Design and Fabrication of a 5-kWe Free-Piston Stirling Power Conversion System
}

\author{
Peter A. Chapman ${ }^{1}$ and Thomas J. Walter. ${ }^{2}$ \\ Foster-Miller, Inc., Albany, NY 12205, USA \\ and \\ Henry W. Brandhorst, Jr. ${ }^{3}$ and Raymond L. Kirby ${ }^{4}$ \\ Space Research Institute, Auburn University, AL, 3689, USA
}

\begin{abstract}
Progress in the design and fabrication of a 5-kWe free-piston Stirling power conversion system is described. A scaled-down version of the successful 12.5-kWe Component Test Power Converter (CTPC) developed under NAS3-25463, this single cylinder prototype incorporates cost effective and readily available materials (steel versus beryllium) and components (a commercial linear alternator). The design consists of a displacer suspended on internally pumped gas bearings and a power piston/alternator supported on flexures. Non-contacting clearance seals are used between internal volumes. Heat to and from the prototype is supplied via pumped liquid loops passing through shell and tube heat exchangers. The control system incorporates several novel ideas such as a pulse start capability and a piston stroke set point control strategy that provides the ability to throttle the engine to match the required output power. It also ensures stable response to various disturbances such as electrical load variations while providing useful data regarding the position of both power piston and displacer. All design and analysis activities are complete and fabrication is underway. Prototype test is planned for summer 2008 at Foster-Miller to characterize the dynamics and steady-state operation of the prototype and determine maximum power output and system efficiency. Further tests will then be performed at Auburn University to determine start-up and shutdown characteristics and assess transient response to temperature and load variations.
\end{abstract}

\section{Introduction}

$\mathrm{T}$ HIS paper presents the progress made to design and fabricate a 5-kWe Stirling power conversion system for use in nuclear space power generation. The Stirling Converter Assembly (SCA) is based on the Space Power Demonstrator Engine (SPDE) and Component Test Power Converter (CTPC) demonstrated under NASA contract ${ }^{1,2}$ but with certain differences due to cost and time constraints. Foster-Miller is responsible for the design and fabrication of an SCA demonstrator, as well as prototype test to characterize dynamics and steady-state operation and determine power output and system efficiency. The Space Research Institute of Auburn University is responsible for performance tests to determine start-up and shutdown characteristics and assess transient response to temperature and load variations.

Design parameters for the SCA are operation at a hot-end temperature of $830 \mathrm{~K}$ and a cold-end temperature of $415 \mathrm{~K}$, with a nominal power output of $5 \mathrm{kWe}$, a peak power output of $6 \mathrm{kWe}$ with overstroke, and a design life of 5 years $(44,000 \mathrm{hr})$ of continuous operation at $100 \%$ power level. The working gas is high-pressure (15 MPa) helium, and the convertor operates at a resonant frequency of $85 \mathrm{~Hz}$. The final design goal is to achieve a minimum of $25 \%$ overall efficiency (electrical power out over heat in) and a specific mass of $6 \mathrm{~kg} / \mathrm{kWe}$. Substitution of materials such as alloy steel for beryllium, use of a commercially available linear alternator, and inclusion of bolted

\footnotetext{
${ }^{1}$ Senior Design Engineering Manager, Foster-Miller, Inc., 431 New Karner Road, Albany, NY 12205.

${ }^{2}$ General Manager, Foster-Miller, Inc. 431 New Karner Road, Albany, NY 12205, AIAA Member Grade: MB.

${ }^{3}$ Director, Space Research Institute, Auburn University, AL 36849, AIAA Member Grade: MC.

${ }^{4}$ Senior Research Fellow, Space Research Institute, Auburn University, AL 36849, AIAA Member Grade: MB.
} 
joints for convenience will preclude achievement of the efficiency and specific mass goals at this time. Facilities limitations will also constrain testing of the hot end to $617 \mathrm{~K}$ at Foster-Miller and $650 \mathrm{~K}$ at Auburn University.

\section{Stirling Converter Assembly Design}

The SCA consists of three primary subassemblies: the hot-end assembly, the displacer drive assembly, and the cold-end assembly (see Fig. 1).

\section{A. Hot-End Assembly}

The hot-end assembly consists of the three heat exchangers: the heater head, regenerator, and cooler. The heater head and cooler are both shell and tube heat exchangers, each with 1800 small diameter tubes $(0.89 \mathrm{~mm}$ ID, 1.65 $\mathrm{mm} \mathrm{OD}$ ). The ends of each tube are electron-beam welded to the tube sheets. Figure 2 shows a photograph of the heater head and cooler prior to electron-beam welding of the tubes. The heater shell, cooler shell, and tubes are constructed of Inconel 718. The regenerator is constructed of a porous metal matrix with $80 \%$ porosity ( $20 \%$ density) brazed to an inner and outer metal liner. The matrix is a sintered structure of randomly arranged metal fibers $0.022 \mathrm{~mm}$ in diameter. The matrix is type 316 stainless steel; the inner and outer liners are Inconel 718 .

Fabrication of these components has required multi-step processes due to the intricacy of the design and particular challenges inherent in their manufacture. Figure 3 shows the heater head during the electrodischarge machining (EDM) process used to drill the small diameter holes for the tubes.

\section{B. Displacer Drive Assembly}

The displacer drive pumps the helium through the heat exchangers (see Fig. 4 for a photograph of several displacer drive components). It consists of the displacer (dynamic component) and the post and flange (stationary component). The displacer consists of a central rod, a displacer dome and its support on the hot end, and the gas spring piston on the cold end. Two gas springs, one on each end, provide the spring stiffness needed to establish resonance. The forward spring is relatively weak ( $24 \%$ of stiffness) versus the aft spring ( $76 \%$ of stiffness). The rod provides the bearing support for the displacer drive. An internally pumped hydrostatic gas bearing is used in the SCA design for long life. All components in the displacer drive are alloy steel, with the exception of the displacer dome, which is Inconel 718 due to exposure of the dome to the hot expansion space. In the CTPC, the equivalent steel parts were fabricated from beryllium for its low density and high stiffness. Because of the additional losses in the gas springs suspending a heavy steel displacer, a penalty of approximately 3.5 points in efficiency is predicted. Since the bearings are not active during initial engine start-up, a compliant wear couple is used on the bearing and seal surfaces to tolerate transitory contact. The inside diameters of the cylinders are plated using Poly-Ond®, and the outside diameters of the rod and pistons are coated with Xylan® 1054.

\section{Cold-End Assembly}

The cold-end assembly consists of the alternator assembly, pressure vessel, and joining ring. The alternator assembly includes the linear alternator, power piston and cylinder, and the suspension system. A flexure support is used instead of a gas bearing to support the piston and plunger. The flexure provides radial and circumferential stiffness which resists the forces between the magnets and stator iron. The entire alternator assembly, including power piston and cylinder, is a single assembled unit supplied by Qdrive, Inc. (Troy, NY) (see Fig. 5). The alternator is designed to deliver $5 \mathrm{kWe}$ at a nominal stroke of $22 \mathrm{~mm}$ and $6 \mathrm{kWe}$ at an overstroke of $24 \mathrm{~mm}$, both at $85 \mathrm{~Hz}$. To reduce lead time and expense, an off-the-shelf size was customized to obtain the power output, voltage level, and temperature capability of the design requirements. These modifications included slightly larger magnets, Hiperco laminations in the stator, samarium cobalt magnets, and custom windings. A performance penalty was accepted in lieu of an optimized custom alternator design. The current design is calculated to provide $88 \%$ efficiency at $5 \mathrm{kWe}$, versus approximately $93 \%$ efficiency with an optimized design.

\section{Bearings and Porting}

The displacer is supported with a hydrostatic gas bearing located on the displacer rod. The bearing is internally pumped, pulling gas from the aft gas spring when its amplitude is high, charging a volume internal to the rod when a port opens at roughly $50 \%$ stroke. Two rows of 12 holes, each $0.30 \mathrm{~mm}$ in diameter, feed the bearing from this volume. The gas then flows along the rod and drains to the forward gas spring. A centering port located approximately at the mid-stroke position returns the bearing gas flow back to the aft gas spring, along with any net flow occurring due to seal leakage. To correct for seal leakage along the power piston seal, a centering port connects the compression space to the piston gas spring at approximately the mid-stroke position of the power piston. 

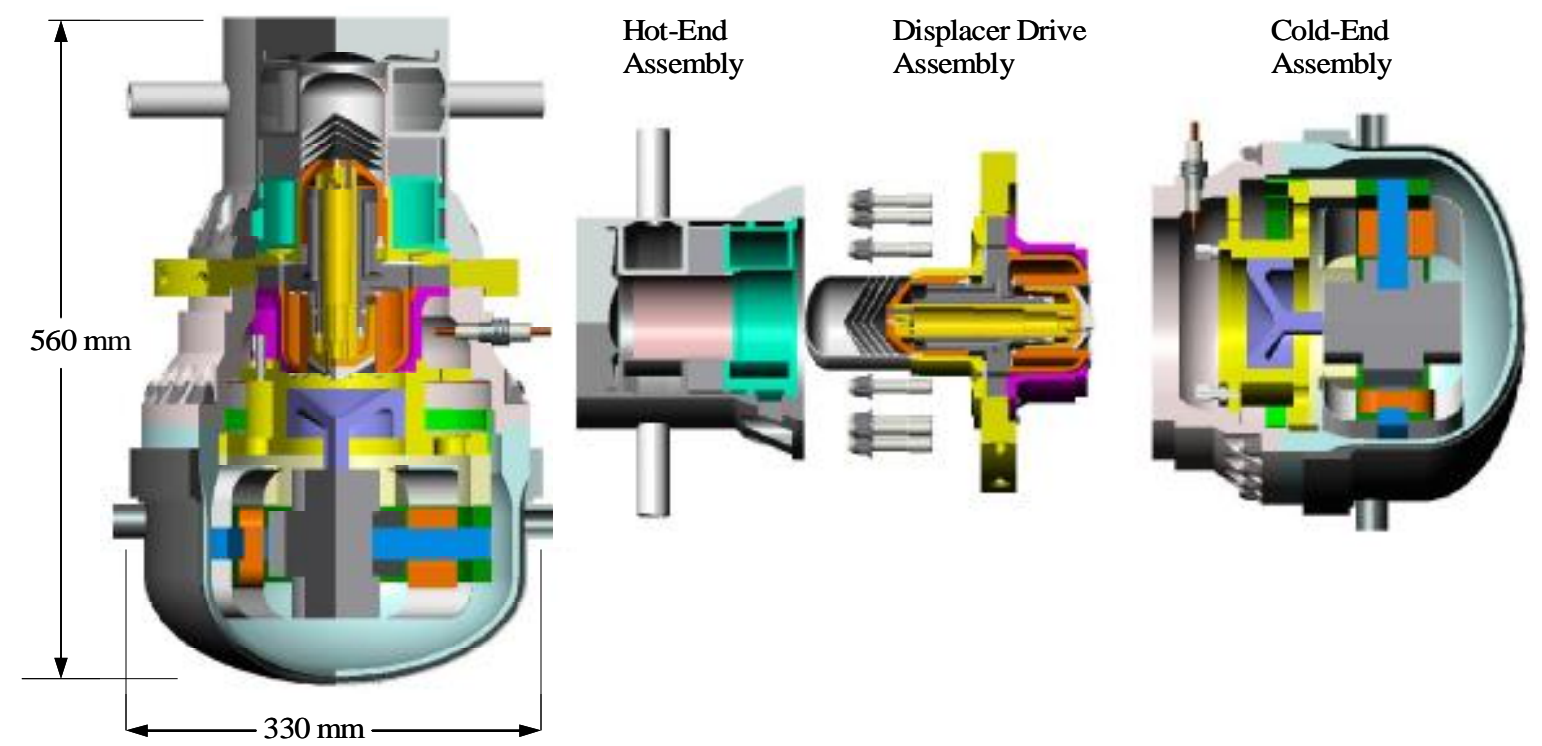

Figure 1. Demonstrator engine. Exploded view presents the three subassemblies of the SCA: hot-end assembly, displacer drive assembly, and cold-end assembly.

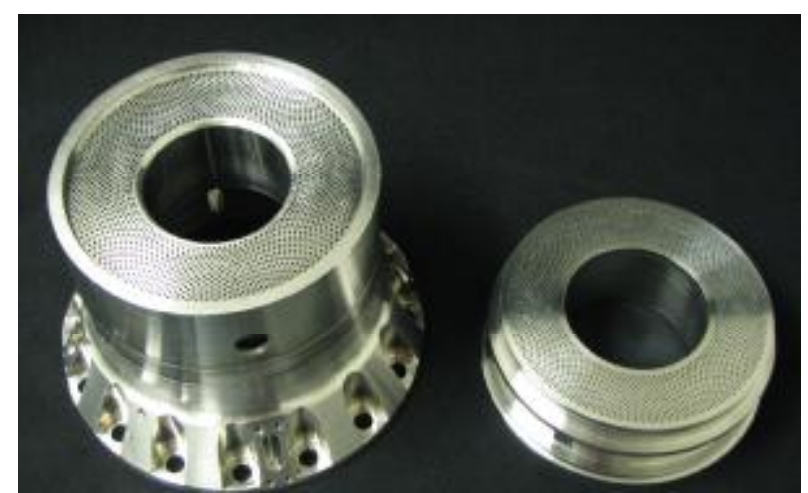

Figure 2. Heater head and cooler assemblies. Assemblies are shown prior to electron-beam welding of tubes. 

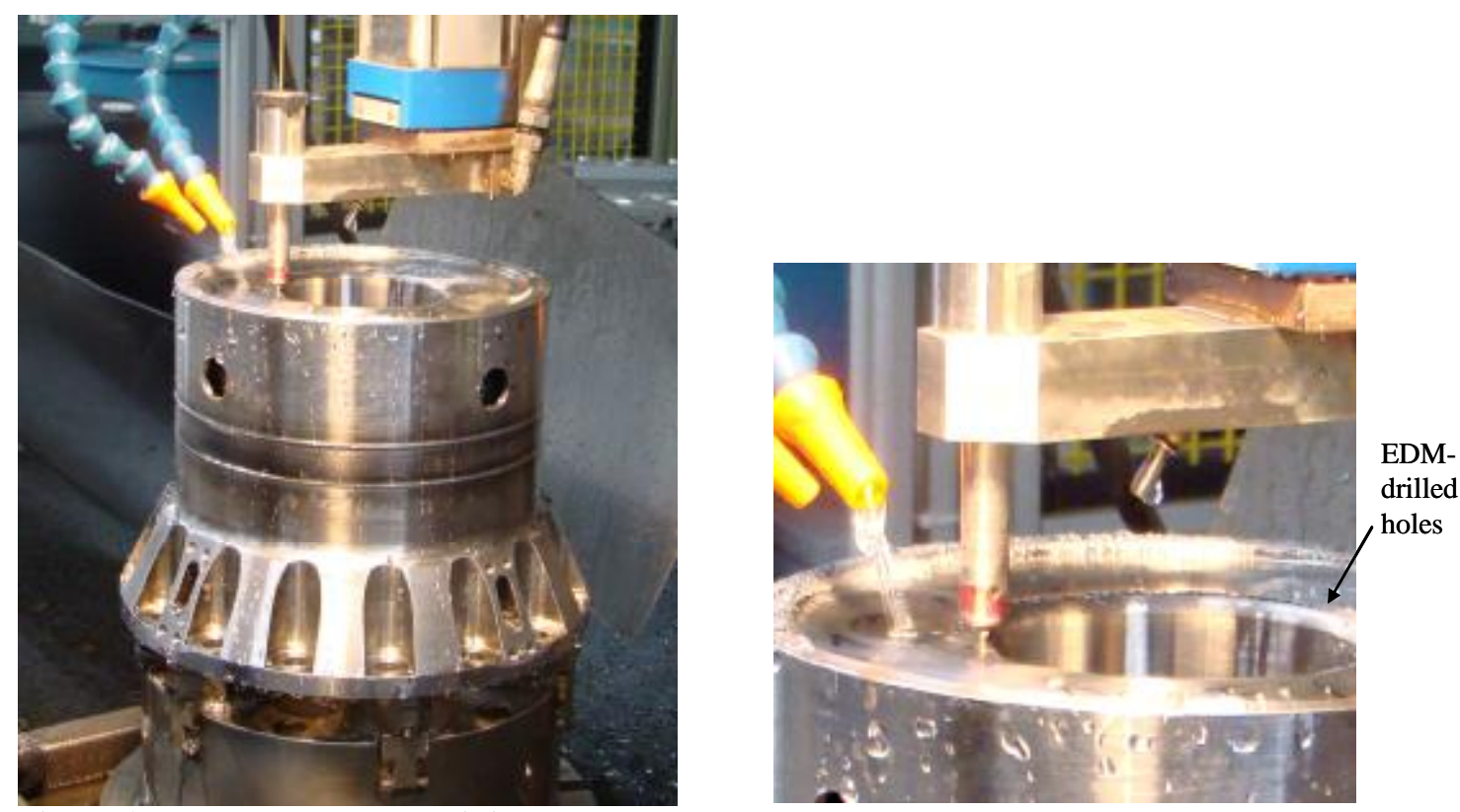

Figure 3. Heater head machining process Holes for the heater head tubes are drilled using an electrodischarge machining (EDM) process.

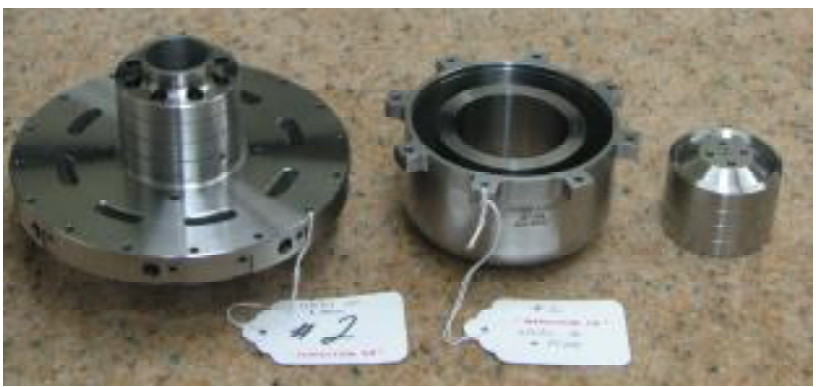

Figure 4. Displacer drive components. Shown left to right: post and flange, gas spring cylinder, gas spring piston.

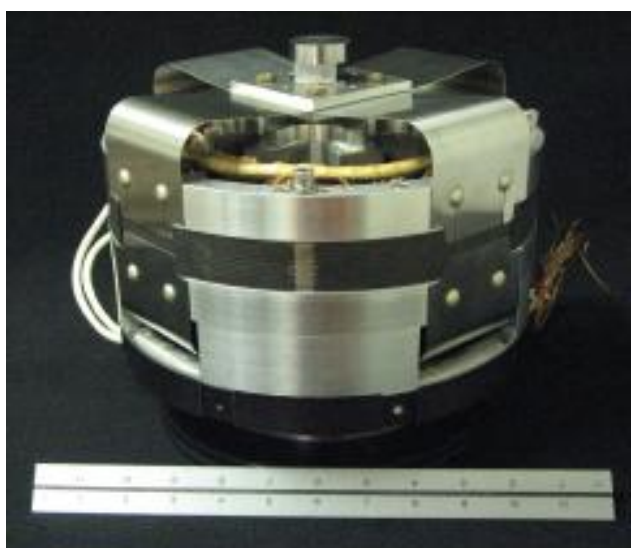

Figure 5. Alternator. Complete alternator assembly supplied by Qdrive, Inc. 


\section{SCA Control System}

The control system incorporates several novel ideas such as a pulse start capability and a piston stroke set point control strategy that provides the ability to throttle the engine to match the required output power. It also ensures stable response to various disturbances such as electrical load variations while providing useful data regarding the position of both power piston and displacer.

A key thrust of the control development effort was to establish the dynamic characteristics ${ }^{3}$ of a FPSE and to develop an acceptable method of controlling the piston stroke of the engine. In order to experiment with various control strategies, without damage to the actual engine, a dynamic model of the engine was developed. We start with a linear model and then extend the analysis to a non-linear model. The non-linear model was then used to analyze different control strategies. Each control strategy was then evaluated using the nonlinear model.

The dynamics of a FPSE can be modeled by a 6th order nonlinear model consisting of three pairs of complex conjugate poles. It is possible to maintain stable operation of a FPSE, at a desired stroke amplitude set point, by modulating a control resistance in parallel with a user load. Since the 6th order model is a type 0 dynamic system, integral action is required to maintain an offset error of zero in the steady state. A block diagram of the stroke controller is shown in Fig. 6.

The least dominant pair of complex poles is the most sensitive to load resistance. A $43 \%$ reduction in resistance engendered a $61 \%$ change in the real part of the least dominant poles but, only a $1.4 \%$ change in the most dominant pair.

A master controller will monitor all subordinate controllers including: the stroke controller, the heating loop controller, and the cooling loop. In the event there is a problem with any of these subordinate controllers, the master controller will implement a safe shutdown of the entire system. A touch screen will provide the user interface for the control system. Process data will be displayed and operator functions can be performed via the touch screen.

A pair of capacitance gap sensors monitors both displacer and power piston positions. The sensors are located $180^{\circ}$ apart and their signals averaged to eliminate variations due to eccentricities, thermal growth, and so forth. Since the sensors have a small range $(\sim 2 \mathrm{~mm})$ compared to the stroke $(22 \mathrm{~mm})$, a taper is machined into the target to turn down the displacement.

The controller monitors both displacement signals to safeguard against an overstroke condition. It also uses the power piston stroke as the process variable in the control scheme. A separate control load is used in parallel with the user load, and by pulse width modulation (PWM) switching of the control load, a change in total load resistance is induced to maintain the piston stroke set point. ${ }^{4}$ Alternator voltage and current will be measured to determine the output power. Flow rate and temperature drop will be measured across the heat exchangers to determine total heat in and rejected heat. Overall engine mean pressure and dynamic pressures of the cycle and displacer and piston gas springs will be monitored to help evaluate engine performance. All measurements will be displayed and recorded on the user interface using LabVIEW (National Instruments). Figure 7 presents the instrumentation and data acquisition display screen. 


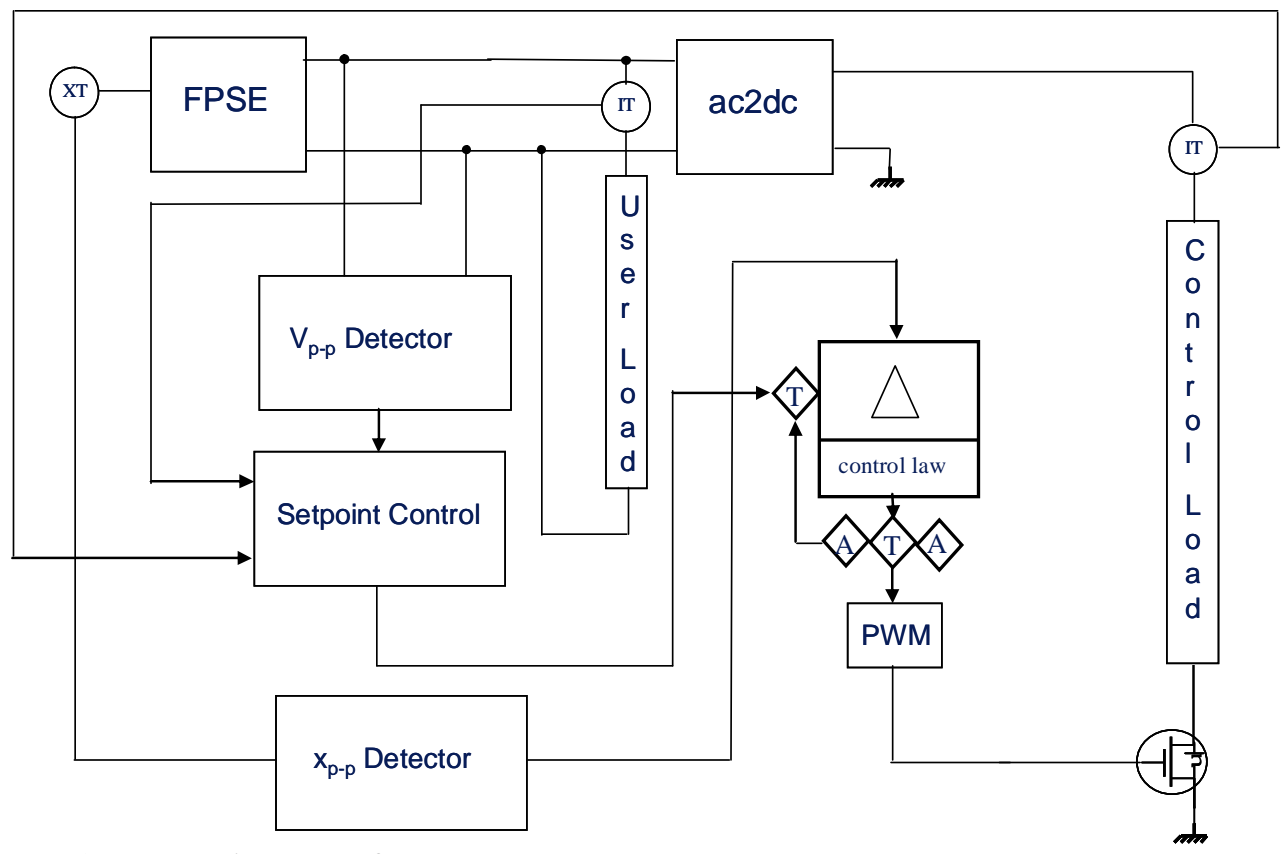

Figure 6. Block diagram of stroke controller. The piston stroke set point control strategy provides the ability to throttle the engine to match the required output power.

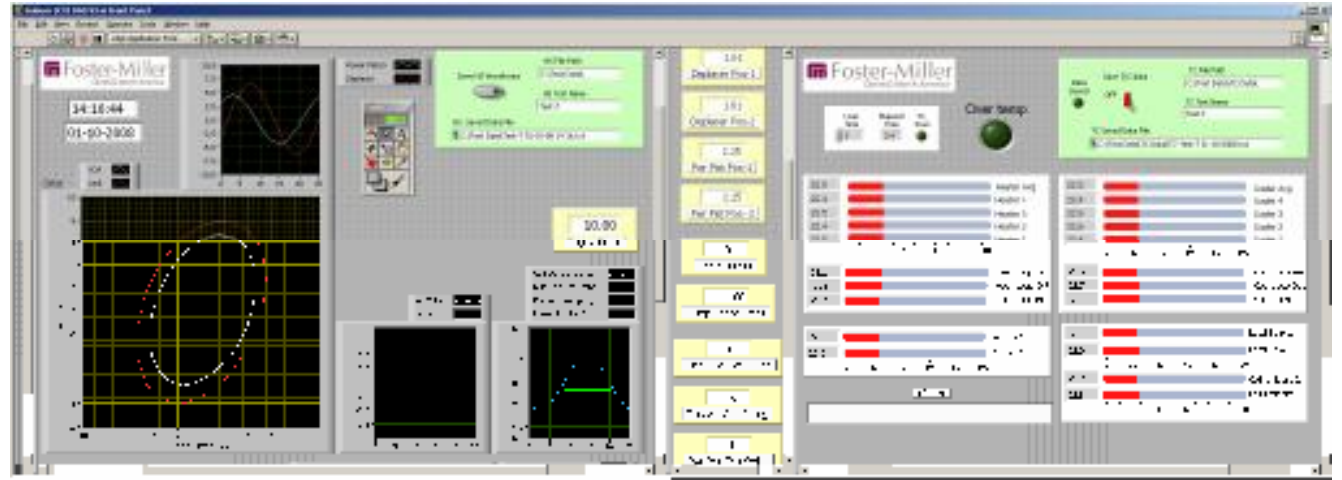

Figure 7. Instrumentation and data acquisition display screen. User interface enables comprehensive monitoring of convertor operations.

\section{SCA Operation and Test}

The output power of the SCA is a function of the hot-end temperature, cold-end temperature, mean pressure, frequency, displacer stroke, piston stroke, and displacer-piston phase angle. In the test facility at Foster-Miller, heat will be provided via an electrically heated pumped loop using Therminol ${ }^{\circledR} 72$ heat transfer fluid. The heating loop will have a separate controller to maintain a set temperature value up to $617 \mathrm{~K}$. Heat will be rejected through a water/glycol pumped loop connected to an air-cooled radiator. A separate controller on the cooling loop will maintain a set temperature by operating a mixing valve.

Initial testing of the SCA will focus on characterizing the power output in relation to varying heater and cooler temperatures under steady-state conditions. Following this, the transient response of the converter to load and temperature changes will be tested and the controller fine-tuned. Load impedance characterization will also be performed to establish the effects of both inductive and capacitive loads on the system. Further testing will evaluate the optimum pulse start parameters, such as temperature, AC voltage, power, and burst time, that will safely and consistently start the system.

American Institute of Aeronautics and Astronautics 092407 


\section{Conclusion}

Efforts continue to demonstrate the viability of a Stirling cycle convertor for nuclear space power generation. The technology has been demonstrated at lower power levels (100 W per cylinder) as well as higher power levels (12.5 kWe per cylinder). Testing in summer 2008 will demonstrate performance at the 5-kWe power level. With the potential for high efficiency, low specific mass, and long life, Stirling systems are an attractive power generation technology not only for space but terrestrial applications. The present system technology will be readily extensible for use in "green" power applications that use gases from sewage digesters, landfills, and industrial processes, as well as use in military field support operations for generators powered by diesel or JP-8 fuels.

\section{Acknowledgments}

This work is supported by Auburn University Space Research Institute under Subagreement 07-SRI-208447-

FMI "Free-Piston Converters." Any opinions expressed are those of the authors and do not reflect the views of Auburn University.

\section{References}

${ }^{1}$ Dochat, G. R., “SPDE/SPRE Final Summary Report,” NASA-CR-187086, 1993.

${ }^{2}$ Dhar, M., “Stirling Space Engine Program, Volume 1—Final Report,” NASA/CR-1999-209164/VOL1, 1999.

${ }^{3}$ Kankam, M.D., Rauch, J, and Santiago, W., "Dynamic Analysis of Free-Piston Stirling Engine/Linear Alternator-Load System-Experimentally Validated”, NASA-TM-106034, 1992.

${ }^{4}$ Kirby, R., and Vitale, N. G., "The Development of a Control System for a 5 Kilowatt Free Piston Stirling Space Convertor," CT-104, Space Technology \& Applications International Forum, 2008. 